\title{
A computational model of prefrontal cortex based on physiologically derived cellular parameter distributions
}

\author{
Joachim Hass', Loreen Hertäg, Sebastian Claudio Quiroga Lombard, Tatiana Golovko, Daniel Durstewitz \\ From Twenty Second Annual Computational Neuroscience Meeting: CNS*2013 \\ Paris, France. 13-18 July 2013
}

A major theme in computational neuroscience is to derive neuronal network models that are on the one hand side physiologically realistic, thus allowing reasonable inferences on their biological counterparts, yet on the other hand are still computationally tractable in some sense (e.g., in terms of simulation time requirements).

Towards this goal, we constructed a computational network model of the PFC based on simple single neuron elements, yet equipped with highly realistic anatomy and close fitting of cellular and synaptic parameter distributions derived from an extensive data base of prefrontal in vitro and in vivo recordings. The resulting model was reasonably fast to simulate and fit to data, amenable to mean-field approaches, yet exhibiting a high degree of physiological validity, even in a predictive sense. At the single-cell level, the network is based on the adaptive exponential integrate-and-fire model (AdEx, [1]) which we simplified further (simpAdEx [2]) to yield closed-form expressions for the firing rates under transient and steady-state conditions. These are used for fully automatized fitting to $\mathrm{f}-\mathrm{I}$ and $\mathrm{V}-\mathrm{I}$ curves of real neurons, with fitting times 1-2 orders of magnitude faster than for the full AdEx, thus allowing relatively quick adaptation to large data bases. The resulting model is also able to predict spiking times of neurons driven by in-vivo-like fluctuating currents that were not used for fitting [2]. In vitro recordings from $\sim 200 \mathrm{~L} 2 / 3$ and L5 pyramidal cells, fastspiking and bitufted interneurons from adult rodent PFC were used to generate a distribution of model cells that reflects the diversity of neurons in the real PFC. At the synaptic level, data obtained from short-term plasticity

\footnotetext{
*Correspondence: joachim.hass@zi-mannheim.de Bernstein-Center for Computational Neuroscience, Central Institute of Mental Health, Medical Faculty Mannheim, Heidelberg University, Mannheim, 68159, Germany
}

(C) 2013 Hass et al; licensee BioMed Central Ltd. This is an Open Access article distributed under the terms of the Creative Commons Attribution License (http://creativecommons.org/licenses/by/2.0), which permits unrestricted use, distribution, and reproduction in any medium, provided the original work is properly cited. protocols were used to fit models of synaptic dynamics, with parameter distributions matched to the types of the connected neurons [3]. At the anatomical level, the network structure involves stripe-like columns as observed in primate PFC [4], a laminar organization and clustered connectivity [5], where the connectivity distributions are extracted from an extensive literature research.

Even without any tuning, the network model already manages to approximate a number of statistics extracted from in-vivo data from awake behaving rats [6]. We also used these in-vivo data sets for further tuning of synaptic parameters. It turned out that a network dynamic with in-vivo-like properties depended sensitively on the matching of cellular model parameter distributions to the true multivariate distributions obtained empirically, i.e. taking both marginal distributions as well as at least their pairwise covariations into account. In summary, we have generated a PFC network model which is biologically highly valid, yet still reasonably fast to simulate and fit, and can now be exploited to probe the impact of pharmacological or genetic conditions on network dynamics, and to model performance in PFC-dependent tasks.

\section{Acknowledgements}

This work was funded by grants from the German ministry for education and research (BMBF, 01GQ1003B) and the Deutsche Forschungsgemeinschaft to D.D. (Du 354/7-2 \& 6-1).

Published: 8 July 2013

\section{References}

. Brette R, Gerstner W: Adaptive exponential integrate-and- fire model as an effective description of neuronal activity. J Neurophysiol 2005, 94:3637-3642. 
2. Hertäg $L$, et al: An approximation to the adaptive exponential integrateand-fire neuron model allows fast and predictive fitting to physiological data. Front Comput Neurosci 2012, 6:62.

3. Markram $\mathrm{H}$, et al: Interneurons of the neocortical inhibitory system. Nat Rev Neurosci 2004, 5:793-807.

4. Lewis DA, Gonzalez-Burgos G: Intrinsic excitatory connections in the prefrontal cortex and the pathophysiology of schizophrenia. Brain Res Bull 2000, 52(5):309-317.

5. Perin R, Berger TK, Markram H: A synaptic organizing principle for cortical neuronal groups. PNAS 2011, 108(13):5419-5424

6. Lapish CC, Durstewitz D, Chandler L, Seamans JK: Successful choice is associated with distinct and coherent network states in anterior cingulate cortex. PNAS 2008, 105(33):11963-11968.

doi:10.1186/1471-2202-14-S1-P116

Cite this article as: Hass et al: A computational model of prefrontal cortex based on physiologically derived cellular parameter distributions. BMC Neuroscience 2013 14(Suppl 1):P116.

\section{Submit your next manuscript to BioMed Central} and take full advantage of:

- Convenient online submission

- Thorough peer review

- No space constraints or color figure charges

- Immediate publication on acceptance

- Inclusion in PubMed, CAS, Scopus and Google Scholar

- Research which is freely available for redistribution

Submit your manuscript at www.biomedcentral.com/submit 